\title{
Registre delphinal par Mathieu Thomassin, publié pour la Société de l'Histoire de France par K. Daly avec la collaboration de G. Labory
}

\section{G. Matteo Roccati}

\section{(2) OpenEdition}

Journals

Édition électronique

URL : https://journals.openedition.org/studifrancesi/20967

DOI : 10.4000/studifrancesi.20967

ISSN : 2421-5856

Éditeur

Rosenberg \& Sellier

Édition imprimée

Date de publication : 1 décembre 2019

Pagination : 556-557

ISSN : 0039-2944

\section{Référence électronique}

G. Matteo Roccati, «Registre delphinal par Mathieu Thomassin, publié pour la Société de l'Histoire de France par K. Daly avec la collaboration de G. Labory », Studi Francesi [En ligne], 189 (LXIII | III) | 2019, mis en ligne le 01 mars 2020, consulté le 11 novembre 2021. URL : http://journals.openedition.org/ studifrancesi/20967 ; DOI : https://doi.org/10.4000/studifrancesi.20967

Ce document a été généré automatiquement le 11 novembre 2021.

\section{c) $(9 \ominus$}

Studi Francesi è distribuita con Licenza Creative Commons Attribuzione - Non commerciale - Non opere derivate 4.0 Internazionale. 


\title{
Registre delphinal par Mathieu Thomassin, publié pour la Société de l'Histoire de France par K. Daly avec la collaboration de G. Labory
}

\author{
G. Matteo Roccati
}

\section{RÉFÉRENCE}

Registre delphinal par Mathieu Thomassin, publié pour la Société de l'Histoire de France par K. Daly avec la collaboration de G. Labory, Paris, Société de l'Histoire de France, 2018; diffusion: Éditions De Boccard, 390 pp.

1 Mathieu Thomassin a été chargé le 20 mai 1456 par le dauphin Louis II (futur Louis XI) de s'informer «de noz anciens droitz, privileges, libertez, gestes, fais et autres choses touchans nosdiz pays» et de les «enregistrer en livre et registre» (p. 5). Le résultat de son travail était destiné à être gardé à la Chambre des comptes à Grenoble: il est conservé dans plusieurs manuscrits, mais aucun n'est complet (le livre II notamment a été arraché dans le meilleur témoin). Commencé sur l'ordre du dauphin, il a été réalisé en son absence - ce sont les années où Louis, en conflit avec son père Charles VII, se réfugie auprès du duc de Bourgogne - et «n'a jamais été terminé, mais est demeuré sous forme de brouillon inachevé» (p. 24). Il est donc surtout révélateur de l'état d'esprit et de l'attachement au pays du «milieu culturel des juristes et des officiers delphinaux» (p. 51), soucieux de loyauté envers le roi: l'«enquête historique sert à démontrer que les territoires qui forment le Dauphiné appartiennent de temps immémoriaux aux souverains de Gaule, puis de France, et [le] traité cherche à trouver les bases légales d'une obéissance due directement au roi plutôt qu'au dauphin» (p. 30).

2 Le registre a été conçu par Thomassin en trois livres: le premier traite de l'histoire du royaume de Bourgogne (auquel se rattache le Dauphiné), le deuxième de celle des 
dauphins jusqu'au «transport» à la maison de France en 1349, le troisième fournit une généalogie des dauphins depuis le transport, suivie par une description de la «limitacion et division du Dauphiné»(p.62). Il était jusqu'à présent surtout connu comme source sur Jeanne d'Arc car il contient plusieurs textes la concernant, dont le Ditié de Christine de Pizan; le présent travail, précis et fouillé, permet de l'appréhender dans son contexte et d'en mesurer l'importance pour comprendre la culture, historique et politique, du milieu dont il émane, les enjeux de pouvoir - entre le roi et le dauphin et les conflits - avec le duc de Savoie, le prince d'Orange, l'archevêque de Vienne - dont il témoigne.

3 L'introduction retrace d'abord la vie de l'auteur: né vers 1391 à Lyon, il se forme à Orléans et à Paris, qu'il quitte sans doute lors des troubles de 1418. Il fait carrière dans le Dauphiné; victime des purges contre les officiers restés fidèles à son père, on perd sa trace après l'avènement de Louis XI. L'œuvre historique et polémique de Thomassin est présentée ensuite; avant le Registre il avait écrit trois autres ouvrages sur les mêmes sujets: Deductio ac declaratio dignitatum (...) prerogativarum (...) dalphino, Manipulus et Breviere des anciens droys, honneurs et prerogatives du Dauphiné de Viennoys. Les pages suivantes sont consacrées au Registre: le contexte d'écriture, les conflits qui permettent de comprendre la logique des matériaux rassemblés, les documents concernant Jeanne d'Arc, la culture de l'auteur, l'intention et la réception de l'œuvre. L'introduction s'achève par l'étude de la tradition, la description des manuscrits (les plus importants: Grenoble, B.M., U 909 Rés., R 8788; Paris, BnF, fr. 4627, 4949; Carpentras, B.M. Inguimbertine, 711 (L 638)) et l'explicitation des principes suivis pour l'établissement du texte.

Le texte édité (pp. 77-263) est accompagné de nombreuses notes historiques en bas de page. Six appendices fournissent l'édition du Breviere (I, pp. 265-305), la description des manuscrits des autres œuvres de Thomassin (II, pp. 307-308), la discussion des rapports entre la généalogie des dauphins établie par Thomassin et la Genealogia delphinorum Viennensium, attestée à Lyon à la fin du Xve s. (III, pp. 309-311), l'identification des noms de lieu du Dauphiné, de fief et d'hommage appartenant aux dauphins de Viennois cités par Thomassin (IV, pp. 313-331), une synthèse sur les origines et l'histoire du Dauphiné, suivie d'une liste simplifiée des rois de Bourgogne et des dauphins de Viennois ( $\mathrm{V}$, pp. 333-337), le relevé des sources utilisées dans le Registre (VI, pp. 339-340). Le volume comporte enfin cinq planches en couleur, l'indication des sources et la bibliographie (pp. 341-356), ainsi que l'index (pp. 357-384). 